be accurately investigated with such elements as calcium, iodine, bromine, silver, etc. ${ }^{6}$

The effect of irradiation on tissues could be examined by observation of the amounts absorbed of a solution activated with a suitable tracer element, before and after exposure to the same solution 'tagged' with a different active isotope.

Department of Physics, Отто BцÜH.

The University, Edgbaston,

Birmingham, 15. July 19.

1 Barnett, A., Phys. Rev., 56, 963 (1939).

${ }^{2}$ Crane, H. R., ibid., 56, 1234 (1939).

${ }^{3}$ Mullins, Lorin J., ibid., 56, 1244 (1939), Hevesy, G., ibid., 57, 240 (1940).

‘ Brewer, A. Keith, Ind. and Eng. Chem., 30, 893 (1938).

${ }^{5}$ Lasnitzki, A., and Brewer, A. K., Natore, 142, 538 (1938).

- Livingood, J. J., and Seaborg, G. T., Rev. Mod. Phys., 12, 30 (1940).

\section{Influence of Combined Phosphoric Acid on the Swelling of Granular Starch}

IN some starches phosphorus occurs in combination as a salt of an amylomonophosphoric ester ${ }^{1}$, $\mathrm{St}-\mathrm{O}-\mathrm{PO} / \mathrm{OR}_{1}, \mathrm{OR}_{2}$, where $\stackrel{\mathrm{St}}{\mathrm{I}}$ is a glucose unit in the polysaccharide chain and $R_{1}$ and $R_{2}$ are metal or hydrogen atoms ; in others the phosphorus is not combined with the starch, and part of the phosphoruscontaining impurity can be removed by extraction with methanol or cold dilute mineral acid. Potato and wheat starch are representative of the two classes $^{1}$. correlation has been found, however, in a group of eight starches that satisfy this condition and contain 0.145-0.232 per cent phosphorus pentoxide. The swelling capacities in salt solution of the samples differ considerably so that there may be differences in sub-microscopical structure which mask the effect of the phosphorus on the swelling in pure water.

The phosphorus contents of fractions of uniform granule size separated by elutriation in water from one sample of potato starch increase with decreasing mean radius. The copper-reducing powers, specific viscosities in 30 per cent calcium thiocyanate solution, and the solubilities of the fractions in $0.01 M$ phosphate buffer solution, $p \mathrm{H} 7$, are almost identical and the differences in swelling capacity in the same buffer solution are small; it may be concluded, therefore, that their average chain-lengths are the same and that the structure factor is common to all. In distilled water, swelling is much higher than in salt solution, and among the sodium starches prepared from the different fractions the swelling increases three-fold as the phosphorus pentoxide content increases from $0 \cdot 148$ to $0 \cdot 254$ per cent (see accompanying table). These differences in swelling are not due to differences in the ratio volume/surface area of the granules ${ }^{4}$, since fractions 1 and 2, differing in average radius but nearly equal in phosphorus content, swell equally.

On the other hand the swelling of the fractions from a wheat starch is independent of granule size, phosphorus content, the salt used in washing, or the presence of salt during swelling. It is therefore evident that esterified phosphoric acid does facilitate the swelling of starch granules to an extent dependent upon its amount, but the effect is manifest only in the absence of free electrolyte and when the average chain-length and the structure of the granules are the same.

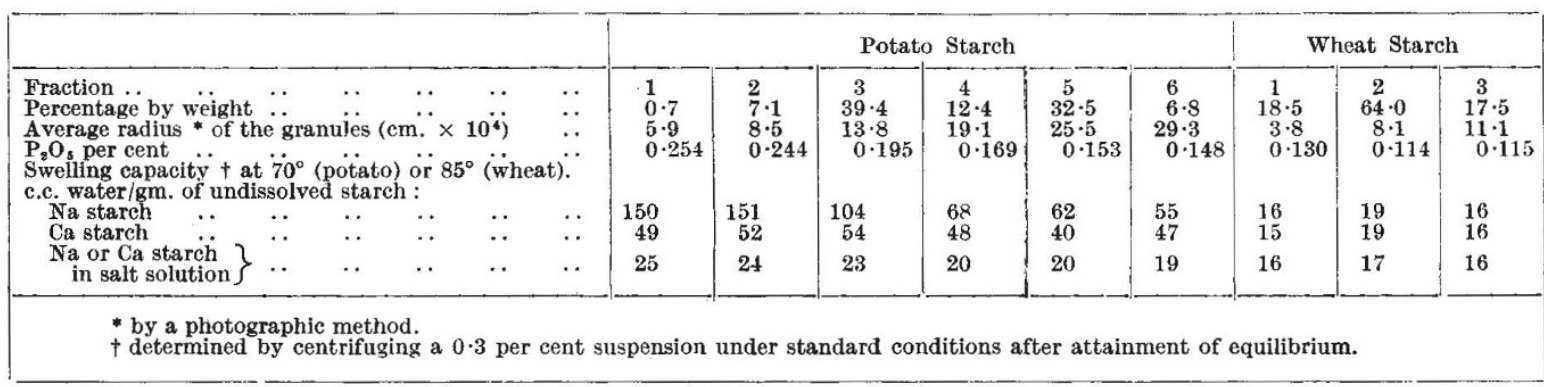

The metal combined with the phosphorus in potato starch can be varied by washing with appropriate salt solutions and then with water until the filtrate is free from electrolyte ${ }^{2}$. The properties of the washed starch vary with the identity and amount of the combined metal; for example, the swelling capacity of the granules in hot water and the viscosity of the hot 3 per cent paste of a sodium starch are greater than those of the corresponding calcium starch. The difference is not observed in presence of salt and is probably due to the greater tendency of the sodium to ionize and diffuse into the surrounding water. It was expected that after washing with the same salt solution the swelling behaviour of potato starches would be related to their phosphorus contents provided that their average molecular chain-lengths ${ }^{3}$ were the same. No simple
Enhanced swelling has also been observed when carboxylic acid groups have been introduced by oxidation into a granular starch of low phosphorus content.

\section{W. A. Richardson.}

R. S. HigGINBotham.

\section{Shirley Institute, Didsbury, \\ Manchester. July 22 .}

${ }^{1}$ Posternak, Helv. chim. Acta, 18, 1351 (1935).

'Tryller, Chem. Z., 44, 833, 845 (1920).

${ }^{3}$ Richardson, Higginbotham and Farrow, J. Text. Inst., 27, T131 (1936).

'Alsberg, Ind. Eng. Chem., 18, 190 (1926). 